\title{
BMJ Open Association between dispositional empathy and self-other distinction in Irish and Belgian medical students: a cross-sectional analysis
}

\author{
Henryk Bukowski, ${ }^{1}$ Nor Faizaah Ahmad Kamal, ${ }^{2}$ Deirdre Bennett (D) ,2 \\ Gabriella Rizzo, ${ }^{3}$ Colm O'Tuathaigh (i) ${ }^{2}$
}

To cite: Bukowski H, Ahmad Kamal NF, Bennett D, et al. Association between dispositional empathy and self-other distinction in Irish and Belgian medical students: a cross-sectional analysis. BMJ Open 2021;11:e048597. doi:10.1136/ bmjopen-2020-048597

- Prepublication history and additional supplemental material for this paper are available online. To view these files, please visit the journal online. (http://dx.doi.org/10.1136/ bmjopen-2020-048597)

Received 31 December 2020 Accepted 06 August 2021

Check for updates

(c) Author(s) (or their employer(s)) 2021. Re-use permitted under CC BY-NC. No commercial re-use. See rights and permissions. Published by BMJ.

${ }^{1}$ Psychological Sciences Research Institute, Universite catholique de Louvain, Louvainla-Neuve, Walloon Brabant, Belgium

${ }^{2}$ Medical Education Unit, School of Medicine, University College Cork, Cork, Ireland

${ }^{3}$ Department of Medicine, Cork University Hospital, Cork, Ireland

Correspondence to

Dr Colm 0'Tuathaigh;

c.otuathaigh@ucc.ie

\section{ABSTRACT}

Objective Physicians' cognitive empathy is associated with improved diagnosis and better patient outcomes. The relationship between self-reported and performance-based measures of cognitive empathic processes is unclear. Design Cross-sectional analysis of the association between medical students' empathy scale scores and their empathic performance in a visuospatial perspective-taking (VPT) task.

Participants Undergraduate medical students across two European medical schools ( $n=194)$.

Primary and secondary outcome measures Two selfreport empathy and one performance-based perspectivetaking outcome: Jefferson Scale of Physician Empathy (JSPE); Empathy Quotient (EQ); Samson's level-1 VPT task. Results Higher scores on the 'standing in patient's shoes' subscale of the JSPE were associated with a lower congruency effect (as well as lower egocentric and altercentric biases) in the VPT $(\mathrm{B}=-0.007,95 \% \mathrm{Cl}=-0.013$ to $0.002, p<0.05$ ), which reflects an association with better capacity to manage conflicting self-other perspectives, also known as self-other distinction. Lower egocentric bias was also associated with higher scores on the 'social skills' $E Q$ subscale $(B=-10.17,95 \% \mathrm{Cl}=-17.98$ to $2.36, p<0.05$ ). Additionally, selection of a 'techniqueoriented' clinical specialty preference was associated with a higher self-perspective advantage in the VPT, reflecting greater attentional priority given to the self-perspective. Conclusions We show that self-assessment scores are associated with selected performance-based indices of perspective taking, providing a more fine-grained analysis of the cognitive domain of empathy assessed in medical student empathy scales. This analysis allows us to generate new critical hypotheses about the reasons why only certain self-report empathy measures (or their subscales) are associated with physicians' observed empathic ability.

\section{INTRODUCTION}

High levels of physician empathy are positively correlated with various indices of patientcentred care, including improved outcomes, treatment compliance, patient satisfaction as well as a reduction in medico-legal cases. ${ }^{1-4}$ Conversely, lower levels of empathy are often
Strengths and limitations of this study

- This study measures and compares for the first time in medical students performance-based measures of cognitive empathic processes via a visuospatial perspective-taking paradigm, alongside widely used self-report scales.

- This study was conducted in undergraduate medical students across two European medical schools.

- Examining correlations between observed perspective-taking performance and specific subscales of self-report empathy measures in this study have informed on the relationship between self-report and observed empathic ability of medical students and physicians.

- One limitation of this study relates to the face validity of the visuospatial perspective-taking task in a healthcare context, as the task does not focus on doctor-patient interactions.

associated with a higher rates of physician burnout, ${ }^{5-7}$ which may be expected to impact negatively on patient care. ${ }^{8}$

The design of appropriate tools to measure physician empathy is undermined by several theoretical and methodological issues that have led researchers to observe inconsistent and inconclusive relationships between empathy scale scores and actual empathic behaviour in simulated or clinical settings. ${ }^{9-11}$ The first issue is that there is a lack of consensus regarding the conceptual structure of empathy and thus the way to measure empathy. ${ }^{12}$ In a clinical context, empathy is multidimensional, including affective, cognitive and behavioural components. ${ }^{13}$ Affective empathy refers to the ability to experience an emotional reaction to the experience of another person. ${ }^{14}$ The capacity to identify and understand another's psychological perspective is referred to as cognitive empathy. The behavioural component reflects the physician's ability to communicate, and act on, that 
understanding of the patient's mental condition. ${ }^{13} 15$ The most widely used self-report measure of medical student empathy, the Jefferson Scale of Physician Empathy (JSPE), ${ }^{16}$ focuses essentially on the cognitive component of empathy, with three subscales: the 'perspective taking', 'compassionate care' (understanding of patients' emotions and experiences) and 'standing in patient's shoes' (ability to see things from the patients' perspective). ${ }^{17} 18$

The second issue is that research on assessment of medical student empathy has principally relied on selfreport instruments. This approach has been criticised for several reasons including poor agreement between self-report and faculty observations, ${ }^{19}{ }^{20}$ weak correlation between self-assessed and standardised patient measures of physician empathy ${ }^{21}$ as well as lack of measurement and conceptual comparability across instruments. ${ }^{15} 22$ Hence, these issues raise justifiable concerns concerning the meaning of these scales in the context of their widespread use in medical education.

The third issue is that the instruments used to measure the same component of empathy actually focus on distinct aspects. For instance, cognitive empathy can be measured in terms of skills, habits, motivation or adherence to underlying moral values. Hence, poor correlations between conceptually similar subscales across different measures, for example, 'perspective taking' across both the JSPE and alternative scales (eg, Interpersonal Reactivity Index (IRI ${ }^{23}$ ) have been reported. ${ }^{24}$ Relatedly, certain authors have also noted that the distinction between the JSPE subscales 'perspective taking' and 'standing in the patient's shoes' is unclear and that they may represent the same underlying factor. ${ }^{25}$

The present study aimed to examine empathy among medicine students while addressing the three aforementioned issues by combining two self-report instruments and a performance-based measure, the latter being a visuospatial perspective-taking (VPT) task, which is exploited for the first time to measure psychological processes intrinsic to cognitive empathy in medical students.

Cognitive empathy is dependent on both an unambiguous awareness of self-other distinction and the mental flexibility to adopt the subjective perspective of the other. ${ }^{26}$ Effective physician-patient communication is dependent on the ability to infer the knowledge and perceptions of the patient regarding the ongoing interaction and their proximal clinical environment. It also involves the physician being able to successfully distinguish his/her perspective on the consultation from that of the patient. These processes can be measured using a VPT task, where the first-person perspective is contrasted with the view of a third-person avatar, which may or may not be congruent with the research participant's viewpoint. VPT allows us to understand and interact with other social beings by accurately determining how and what they see in their environment. ${ }^{27}$ Perspective-taking performance in this task requires identifying and representing another person's visual experience, and correctly choosing the goal-relevant perspective when the self-perspective and third-person perspective are incongruent. ${ }^{27}{ }^{28}$ Previous studies have reported that VPT performance is associated with increased empathy (measured using the IRI) in college students. ${ }^{29}{ }^{30}$ Here, we employed an existing level-1 perspective-taking task ${ }^{2730}$ to examine the relationship between perspective congruence and prioritisation of self-perspective versus other-person perspective and medical students' responses in two self-report empathy measures, the JSPE, ${ }^{16}$ and the Empathy Quotient $\left(\mathrm{EQ}^{31}\right)$. We hypothesised that higher perspective-taking performance (via the VPT) would be associated with higher empathy scores, particularly across subscales measuring cognitive empathic processes, in medical students.

\section{METHODS \\ Study design and participants}

This study was conducted in University College Cork (UCC) and University of Louvain (UCLouvain) medical school in a cohort of 194 students who had at least one full-time clinical placement as part of their medical curriculum, during the first half of the academic years $2017 / 2018$ and $2018 / 2019\left(\mathrm{M}_{\text {age }}=24.27, \mathrm{SD}=2.83 ; 128\right.$ females). The School of Medicine at UCC offers a systems-based integrated undergraduate curriculum with early patient contact and full-time clinical placements in the latter 2.5 years of the programme. At UCLouvain, the 6-year undergraduate programme is phased across two 3-year cycles with an increasing degree of acquired competences and clinical exposure. The inclusion criterion for the UCC students was to be in the latter 2.5 years of their undergraduate curriculum in order for them to have clinical experience. The inclusion criterion for the UCLouvain students was to be at least in their fourth year (second cycle) in order for them to have clinical experience, with no maximal limit of years. It was not appropriate or possible to involve patients or the public in the design, or conduct, or reporting or dissemination plans of our research.

\section{Patient and public involvement}

No patient was involved.

\section{Instruments}

\section{Jefferson Scale of Physician Empathy}

The student version of the JSPE was used to measure the empathy in medical students. It is a self-administered tool that contains 20 items across three subscales ('perspective taking', 'compassionate care' and 'standing in patient's shoes') answered on a 7-point Likert-type scale. ${ }^{16}$ The JSPE total score ranges from 20 to 140, with higher values indicating a higher degree of empathy. ${ }^{11} 1532-35$

\section{Empathy Quotient}

Initially designed to measure empathy in individuals with individuals who exhibit autistic traits, and validated in a clinical sample, ${ }^{31}$ the EQ scale is a 60 -item questionnaire, 
The number of discs visible from the other person's perspective and self-perspective are:
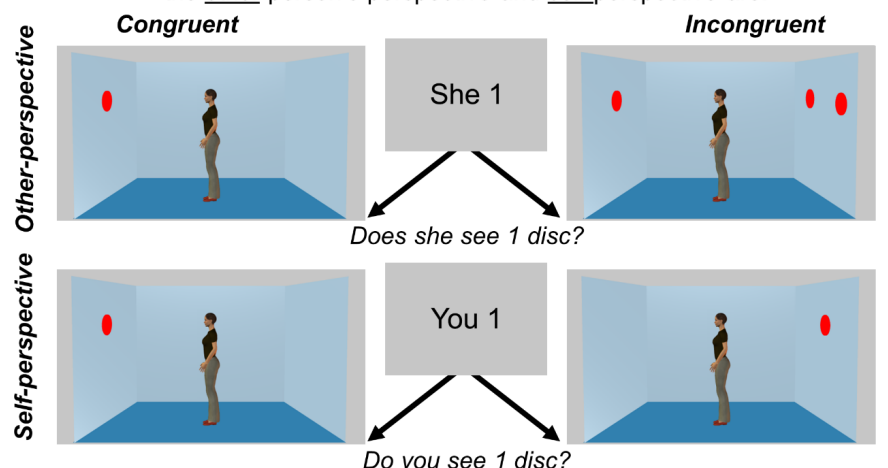

Figure 1 Schematic of the visual perspective-taking task, which compares speed and accuracy performance between, on one hand, the congruent and incongruent perspectives trials and, on the other hand, the other-perspective and self-perspective trials. The correct answer for the four trials shown here is 'yes/match'.

where each item is a first-person statement which the study participant must rate as either 'strongly agree', 'slightly agree', 'slightly disagree' or 'strongly disagree'. Previous factor-analytic studies distinguished three EQ subscales labelled 'cognitive empathy', 'emotional empathy' and 'social skills'.'

\section{VPT task}

The VPT task used in this study has been described previously $^{27}$ and correlates well with self-reported everyday life perspective-taking tendencies. ${ }^{30}$ In this computer-based task, participants view pictures of a human avatar positioned in the centre of a room with zero to three red discs displayed on one or two of the side walls (see figure 1). The avatar is viewed sideways facing either the left or the right wall. The task involves deciding whether a prompted number (ranging from 0 to 3 ) matches or mismatches the number of discs visible from a prompted target perspective, which could be either the participant's perspective (self-perspective condition) or the avatar's perspective (other-perspective condition, ie, what number of discs are visible from the avatar's viewpoint). The number of discs visible could be the same for both perspectives (congruent perspectives condition) or different (incongruent perspectives condition). Reaction time (RT) and error rates were collected.

The following four indices (1-4) of VPT performance were computed based on previous works. ${ }^{27-30} 36-39$ For all these indices, a higher score equates to lower VPT performance as it indicates either more biased cognition (1-3) or more self-centred cognition (2 and 4).

(1) The congruency effect reflects the extent of bias (or interference) caused by the irrelevant conflicting perspective, and captures the difficulty to handle conflicting perspectives and self-other distinction.

(2 and 3) The egocentric and altercentric biases are the extent of biases separately for self-perspective and avatar's perspective trials, and capture, respectively, the ability to adopt someone else's perspective without being erroneously influenced by our own point of view and the ability to evaluate one's own perspective without being erroneously influenced by someone else's point of view.

(4) The self-perspective advantage is the extent of performance advantage at judging from the self-perspective over the avatar's perspective, and captures the attentional priority given to the self-perspective, also referred to as self-centeredness or egocentricity.

A questionnaire was also administered which collected sociodemographic and educational/career details of the participants, such as sex, age, medical school admission pathway, nationality, year of medical education and choice of career specialty. Choice of specialty was categorised according to person-oriented specialties (related to general practice, internal medicine, paediatrics, psychiatry and obstetrics and gynaecology) and techniqueoriented specialties (related to the surgical area and specialties such as ophthalmology, otorhinolaryngology, anaesthesia, radiology and pathology). ${ }^{40}$

\section{Procedure}

The questionnaire and VPT task links were distributed via email to medical students from January to May during the academic years 2017-2018 and 2018-2019. Briefly, all eligible students were invited to participate in a study which aimed to investigate the factors which impact on interpersonal understanding among medical students in clinical years. They were told that each of the online questionnaire and visual task elements would take approximately $10-15 \mathrm{~min}$ to complete. Participation was voluntary and not linked with course credits. The JSPE, EQ and sociodemographic questions were hosted online on the Typeform survey platform (https://www.typeform. com/). A link at the end of the questionnaire directed participants to the VPT task, hosted on the Testable (https://www.testable.org) behavioural testing platform. Participant anonymity was maintained throughout and the researchers blinded by using the web-based platform for collection and collation of data. A welcome web-page stated the participant's rights, general information about the study and that by pressing the button to continue the participant gives her/his consent for the study.

\section{Data analysis}

Summary statistical analysis was completed for categorical and non-categorical variables. Consistent with previous VPT studies, ${ }^{27} 36$ only matching trials (ie, 'yes' response trials) were analysed and RT was analysed only on correct response trials. Medians were used instead of means to estimate VPT performance because all participants produced outlying RT ( $15 \%$ of trials on average), which excessively influences the mean but not the median. ${ }^{41}$ Given the limited statistical power of each university sample separately, we analysed performance only on the full sample. Fourteen participants with outlying accuracy (ie, rate of correct responses at chance level, determined as within the $95 \%$ CI around chance level: $\leq 0.625$ ) in 


\begin{tabular}{|c|c|c|}
\hline Characteristic & $\mathbf{N}$ & $\%$ \\
\hline \multicolumn{3}{|l|}{ Sex } \\
\hline Female & 121 & $(67.2 \%)$ \\
\hline Male & 59 & $(32.8 \%)$ \\
\hline \multicolumn{3}{|l|}{ Age (years) } \\
\hline Mean age (SD) & 24.3 & (3.0) \\
\hline Range & $21-42$ & \\
\hline \multicolumn{3}{|l|}{ Nationality } \\
\hline Belgium & 79 & $(43.9 \%)$ \\
\hline Ireland & 41 & $(22.8 \%)$ \\
\hline Other European & 16 & $(8.9 \%)$ \\
\hline South East Asian & 21 & $(11.7 \%)$ \\
\hline Canadian & 12 & $(6.7 \%)$ \\
\hline Other & 9 & $(5.0 \%)$ \\
\hline \multicolumn{3}{|l|}{ Country } \\
\hline Irish & 68 & $(40.7 \%)$ \\
\hline Belgian & 99 & (59.3\%) \\
\hline \multicolumn{3}{|c|}{ Preferred career specialty } \\
\hline Person-oriented & 138 & (76.7\%) \\
\hline Technique-oriented & 41 & $(22.8 \%)$ \\
\hline
\end{tabular}

Figures presented are number (\%) unless stated otherwise.

baseline trials (ie, in congruent perspectives trials where no interference between perspectives could cause erroneous responses) were excluded from analyses. Consequently, 180 participants were included in these analyses and it changed the average rate of correct responses from $\mathrm{M}=0.937(\mathrm{SD}=0.132)$ to $\mathrm{M}=0.970(\mathrm{SD}=0.054)$. Analysis of variance (ANOVA) with 'perspective' (self-perspective vs avatar's perspective) and 'congruency' (congruent vs incongruent perspectives) as within-subject independent variables was conducted on correct $\mathrm{RT}$ and accuracy rates.

Correlational analysis using Pearson's correlation co-efficient $(r)$ was used to establish associations between VPT measures and total and subscale scores for the JSPE and EQ. Multiple linear regression analyses were conducted to identify significant predictors of selected VPT performance measure variation. For all analyses, a p value $<0.05$ was considered statistically significant. All statistical analyses were completed using SPSS V.20 (IBM, New York, New York, USA).

\section{RESULTS}

\section{Study demographics}

One hundred eighty participant responses were included in the present sample. Age of participants ranged from 21 to 42 years $(\mathrm{M}=24.3, \mathrm{SD}=3.0)$, and $67.2 \%(\mathrm{n}=121)$ of the sample was female participants. Table 1 provides a summary of the demographic and educational characteristics of the study sample.

\section{VPT performance}

\section{Reaction times}

The ANOVA revealed a non-significant main effect of 'perspective' $\left(\mathrm{F}(1,179)=0.712, \mathrm{p}=0.400, \eta_{\mathrm{p}}{ }^{2}=0.004\right)$, indicating an absence of performance advantage at judging from one perspective over another, and a significant main effect of 'congruency' $(\mathrm{F}(1,179)=139.223, \mathrm{p}<0.001$, $\left.\eta_{\mathrm{p}}{ }^{2}=0.438\right)$, signifying slower RT for incongruent perspectives trials, and a significant interaction between 'perspective' and 'congruency' $(\mathrm{F}(1,166)=27.604, \quad \mathrm{p}<0.001$, $\left.\eta_{\mathrm{p}}{ }^{2}=0.134\right)$. The interaction was further analysed via pairwise t-test comparisons.

Longer RTs for incongruent other trials than congruent other trials $(\mathrm{t}(179)=14.008, \mathrm{p}<0.001)$ indicated the presence of an egocentric bias whereas longer RTs for incongruent self trials than congruent self trials $(\mathrm{t}(179)=5.382$, $\mathrm{p}<0.001$ ) indicated the presence of an altercentric bias. Furthermore, shorter RTs for congruent other than congruent self $(\mathrm{t}(179)=5.169, \mathrm{p}<0.001)$ indicated the presence of an other-perspective advantage on congruent perspectives whereas longer RTs for incongruent other than incongruent self $(\mathrm{t}(179)=2.355, \mathrm{p}=0.020)$ indicated the presence of a self-perspective advantage on incongruent perspectives. At last, the egocentric bias $(\mathrm{M}=99.614, \mathrm{SD}=95.407)$ is significantly higher than the altercentric bias $(\mathrm{M}=47.125, \mathrm{SD}=117.471 ; \mathrm{t}(179)=5.254$, $\mathrm{p}<0.001)$.

\section{Accuracy rates}

The same ANOVA was then conducted on accuracy rates, which revealed a non-significant main effect of 'perspective' $\left(\mathrm{F}(1,79)=3.226, \mathrm{p}=0.074, \eta_{\mathrm{p}}{ }^{2}=0.018\right)$, a significant main effect of 'congruency' $(\mathrm{F}(1,179)=54.844, \mathrm{p}<0.001$, $\left.\eta_{\mathrm{p}}{ }^{2}=0.235\right)$, indicating a lower accuracy for incongruent perspectives trials, and a non-significant interaction between 'perspective' and 'congruency' $(\mathrm{F}(1,179)=0.200$, $\mathrm{p}=0.655, \eta_{\mathrm{p}}{ }^{2}=0.001$ ).

These RT and accuracy results replicate previous VPT studies, ${ }^{27} 36-3842$ providing confirmation that VPT performance was accurately assessed.

\section{Correlations between VPT performance and scores for the EQ and JSPE}

Pearson's correlations were computed between the four VPT indices (accuracy, RT) and the total and subscales scores of the EQ and JSPE; results are displayed in table 2.

Results indicate that higher egocentric bias, based on RT scores, are associated with lower values on the 'social skills' subscale of the EQ. Additionally, a greater score on the JSPE 'standing in the patient's shoes' subscale was significantly correlated with lower accuracy across three of the VPT indices (congruency, egocentric bias, altercentric bias), and a marginally significant negative correlation was observed between total JSPE and egocentric bias $(p=0.051)$. To determine the extent to which JSPE empathy measure subscales influence these VPT indices, multiple linear regression analysis was conducted. For the accuracy of the congruency effect, a significant regression 


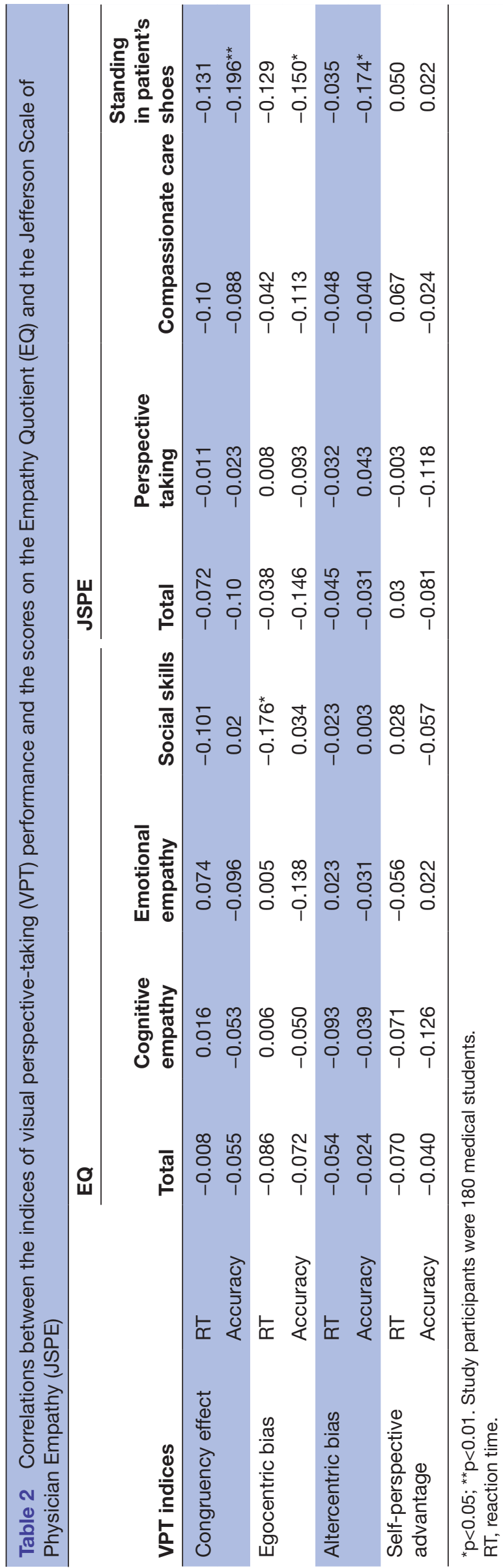

equation was found $(\mathrm{F}(3,176)=2.73, \mathrm{p}=0.046)$, with an $\mathrm{R}^{2}$ of 0.044 . 'Standing in the patient's shoes' was the only predictor of reduced congruency effect accuracy score $(\mathrm{B}=-0.007,95 \% \mathrm{CI}=-0.013$ to $0.002, \mathrm{p}<0.05)$. Regression models examining the predictive effects of JSPE subscales on accuracy-based scores for egocentric bias and altercentric bias did not achieve statistical significance. Multiple linear regression analysis examined the impact of EQ subscales on RT-based egocentric bias variation; a marginally significant regression equation was found $(\mathrm{F}(3,176)=2.751, \mathrm{p}=0.08)$, with an $\mathrm{R}^{2}$ of 0.038 , where higher scores on the 'social skills' subscale was significantly associated with reduced egocentric bias $(\mathrm{B}=-10.17$, $95 \% \mathrm{CI}=-17.98$ to $2.36, \mathrm{p}<0.05)$.

\section{Influence of demographic and educational characteristics}

For accuracy-based VPT measures, Irish medical students demonstrated higher congruency $(\mathrm{t}(178)=3.71, \mathrm{p}<0.001)$, egocentric bias $(\mathrm{t}(178)=2.51, \mathrm{p}=0.013)$ and altercentric bias $(\mathrm{t}(178)=3.51, \mathrm{p}<0.001)$ relative to Belgian students. No differences were observed across the four RT-based VPT measures (all p >0.05). However, Irish students demonstrated higher values on the $\mathrm{EQ}$ 'social skills' subscale $(\mathrm{t}(178)=3.49, \mathrm{p}=0.001)$, and a difference in the opposite direction was observed for the JSPE 'standing in patient's shoes' subscale $(\mathrm{t}(178)=4.48, \mathrm{p}<0.001)$. Similarly, no association was found between age and any of the four VPT measures or empathy scale scores (all $\mathrm{p}>0.05$ ). Although VPT performance was not influenced by sex (all $\mathrm{p}>0.05$ ), female participants showed higher scores for the total $\mathrm{EQ}(\mathrm{t}(178)=2.36, \mathrm{p}=0.019)$ and 'emotional empathy' EQ subscale $(\mathrm{t}(178)=4.20, \mathrm{p}<0.001)$, as well as the JSPE total $(\mathrm{t}(178)=2.99, \mathrm{p}=0.003)$, JSPE 'perspective taking' $(\mathrm{t}(178)=2.05, \mathrm{p}=0.042)$, JSPE 'compassionate care' $(\mathrm{t}(178)=2.58, \mathrm{p}=0.011)$ and JSPE 'standing in patient's shoes' $(\mathrm{t}(178)=2.51, \mathrm{p}=0.013)$ subscales. Career specialty preference was associated with the 'self-perspective advantage' RT VPT measure; students selecting the 'techniqueoriented' specialty category showing higher values for this indice relative to 'person-oriented' students ( $\mathrm{U}=2062$, $\mathrm{z}=2.63, \mathrm{p}=0.008$; figure 2). 'Person-oriented' specialty

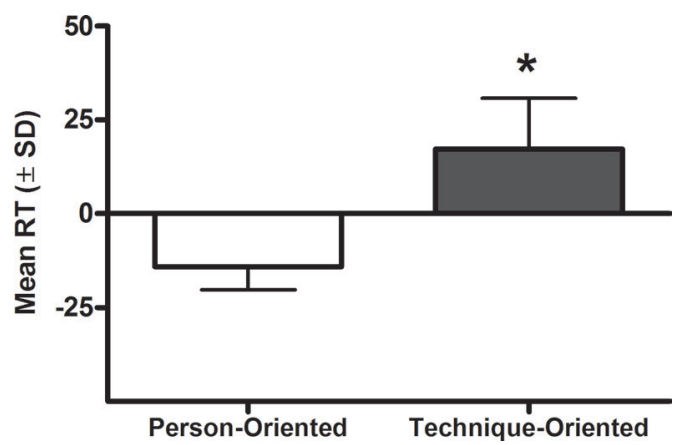

Figure 2 Mean $( \pm S D)$ reaction time $(R T)$ for visuospatial perspective-taking measure 'self-perspective advantage' across the two career preference categories (personoriented, technique-oriented). " $\mathrm{p}<0.05$ vs 'person-oriented' category respondents. 
preference was associated with higher scores across the followingJSPE scale measures (online supplemental figure $1)$ : total score $(\mathrm{U}=2074.50, \mathrm{z}=2.59, \mathrm{p}=0.01)$; 'compassionate care' subscale $(\mathrm{U}=1883.00, \mathrm{z}=3.25, \mathrm{p}=0.001)$. 'Person-oriented' specialty students also showed higher scores for the 'emotional empathy' EQ subscale relative to 'technique-oriented' students $(\mathrm{U}=1958.00, \mathrm{z}=3.00$, $\mathrm{p}=0.003)$.

\section{DISCUSSION}

This study aimed to measure and compare for the first time performance-based measures of cognitive empathic processes in a medical student sample, alongside widely used empathy self-report scales. Results revealed a series of meaningful associations and differences expressed on specific subscales and subcomponents.

The first finding relates to the egocentric bias, capturing the capacity of the medical student to adequately adopt the other person's point of view when her/his own point of view may differ from those of the other person. Lower egocentric bias was significantly associated with higher scores on the 'social skills' subscale of the EQ. As described by Lawrence $e t a l,{ }^{31}$ the 'social skills' subscale assesses the presence (or absence) of intuitive social skills and spontaneous and context-independent use of social skills. It has been noted that such skills are dependent on a certain amount of cognitive empathy. ${ }^{31}$ Consistent with this observation, 'social skills' subscale scores in the current study were significantly correlated with the EQ 'cognitive empathy' subscale $(\mathrm{r}=0.35, \mathrm{p}<0.001)$. Inspection of two items used to score the 'social skills' subscale ("In a conversation, I tend to focus on my own thoughts rather than on what my listener might be thinking" and "I find it difficult to explain to others things that I understand easily, when they don't understand it first time") reveals an obvious overlap between the constructs of egocentric bias and this EQ subscale.

In line with our hypotheses, three indices of VPT performance (congruency, egocentric bias, altercentric bias) were significantly correlated with one of the selfreport cognitive empathy measures, the 'standing in patient's shoes' subscale of the JSPE. Inspection of the two items used to score this subscale ('It is difficult for a doctor to view things from patients' perspectives' and 'Because people are different, it is difficult to see things from patients' perspectives') reveals an obvious similarity between the constructs of VPT-based perspective taking and this JSPE subscale. Importantly, the congruency index is the combination of the egocentric bias (ie, the interference caused by irrelevant self-related information) and the altercentric bias (ie, the interference caused by irrelevant other-related information); the fact that the three indexes are reduced in relation to higher scores in 'standing in patient's shoes' is informative about what specific cognitive empathic process is related to self-reported empathy in medical students. Specifically, it is the capacity to detect and resolve the interference caused by the incongruent irrelevant perspective, that is, self-other distinction, a uniquely human and cognitively complex capacity of empathy. ${ }^{43}$ In summary, those medical students who self-reported higher scores on the 'standing in patient's shoes' subscale performed better at teasing apart their own perspective from another person's perspective.

No relationship was observed between the JSPE subscale 'perspective taking' and any of the VPT measures, further informing the debate whether the JSPE subscale 'perspective taking' is adequate to capture cognitive empathic skills. ${ }^{24}$ Indeed, comparisons of the 'perspective taking' and the 'standing in patient's shoes' JSPE subscales reveal differences in that the latter directly asks about the physicians' relational difficulties, whereas the 'perspective taking' subscale asks about adherence to a set of principles and values (eg, 'A physician who is able to view things from another person's perspective can render better care' and 'Empathy is an important therapeutic factor in medical treatment'). Hence, the absence of any relationship between the 'perspective taking' JSPE subscale and conceptually related performance measure might reflect the observation that the former neither captures actual performance nor does it include items directly asking about performance. These interpretations are however based on correlational results, which can be spurious or confounded by non-measured variables (eg, IQ attentional skills), and thus remain speculative without further empirical support.

Previous studies using self-report empathy scores have shown an unclear association with laboratory-based measures of empathic behaviour. In a comparative longitudinal study by Smith et al, ${ }^{11}$ medical students completed selfreport (including the JSPE) and behavioural (including the reading the mind in the eyes test (RMET)) measures twice a year during the first 3 years of their studies. They demonstrated that while JSPE scores declined over this period, the opposite pattern was observed for RMET performance, highlighting once more the complex relationship between alternative measures of empathy. As mentioned in the 'Introduction' section, a large part of this heterogeneity in research findings results from: (1) failure to deconstruct empathy in terms of more clearly defined components of empathy; (2) over-reliance on self-report measures; (3) a lack of critical examination regarding how a specific component is measured (eg, motivation vs actual competency). Future studies on cognitive empathic abilities of medical students should carefully select the self-report scales so that items directly assess specific cognitive empathy components, such as in terms of motivational states (caring about others) or performance.

Higher accuracy scores for VPT measures were associated with higher scores on the 'standing in patient's shoes' JSPE subscale. It has been noted that self-report empathy measures are susceptible to social desirability bias, which can yield spurious findings. ${ }^{44}$ Social desirability has been conceptualised to include self-deceptive enhancement (ie, an exaggeration of one's positive traits and the denial of 
negative traits) and impression management (ie, deliberate attempts to present oneself positively ${ }^{45}$ ). Narcissism is a personality trait which may be related to positivity biases, resulting in overall more positive ratings on self-report measures of empathy. ${ }^{46}$ It has been suggested that narcissistic personality may represent a trait which is likely to reduce perspective-taking motivation. ${ }^{47}$ Future studies may wish to examine the extent to which personality traits and states may mediate the relationship between self-report and performance-based measures of empathic processes (eg, see Bukowski and Samson ${ }^{42}$ for the interplay between perspective taking, automatic imitation and narcissism).

In the current study, students selecting the less peopleorientated 'technique-oriented' clinical specialty preference showed an increased self-perspective advantage in the VPT relative to those selecting 'person-oriented' specialties, indicative of greater attentional priority given to the selfperspective in these students. In a complementary manner, 'people-oriented' respondents demonstrated higher total JSPE scores and greater scores on the JSPE 'compassionate care' subscales. These data are consistent with previous results showing higher JSPE scores in medical students who indicate a high preference for person-oriented specialties score higher on the JSPE. ${ }^{18}$ This likely reflects a preference for specific specialties which match students' own cognitive empathy attributes. ${ }^{48}$

It may be argued that the size of the correlation coefficients reported in this study are insubstantial, as they explained from $2.3 \%$ to $3.8 \%$ of the variance in VPT performance $(r=0.150-0.196)$. However, a recent meta-analysis of 85 studies showed that correlations between self-report and performance-based measures of empathy explain on average only $1 \%$ of the variance. ${ }^{49}$ Additionally, a recent sixexperiment study (involving 1347 participants) reported a stable correlation coefficient of $0.20 .^{50}$ Furthermore, inspection of the only five studies that examined correlations between self-reported empathy and clinical empathic performance among medicine students reported either non-significant correlations, ${ }^{51}$ a single significant correlation, ${ }^{52-54}$ with coefficients ranging from 0.19 to 0.247 , or several correlations in the range similar to the present study. $^{55}$

Additional study limitations may include questions related to the face validity of the VPT in a healthcare context. The task does not focus on doctor-patient interactions, merely the perspectives of a non-specific avatar. However, it is expected that the cognitive processes under study are pertinent irrespective of the target and VPT measures do correlate well with self-reported empathic tendencies in other groups. ${ }^{30}{ }^{37}$ Lastly, a remote testing platform such as Testable to measure VPT performance enables easier recruitment of medical students in their clinical years, a group who are often difficult to access due to their clinical workload. However, it does introduce a degree of interindividual variability due to differences in the test setting.

In a health professions education research context, we have introduced a finer grained measure of perspective taking, the VPT task, that can be further deconstructed into multiple indices of performance that is differently related to motivational and skill aspects of cognitive empathy. Examining correlations between the VPT indices and the specific subscales of self-report empathy measures in this study have allowed us to generate new critical hypotheses about the reasons underlying discrepant findings concerning the relationship between self-report and observed empathic ability of medical students and physicians.

\section{Twitter Deirdre Bennett @DeirdreMBennett}

Acknowledgements We thank the students of the School of Medicine, University College Cork, and the Faculty of Medicine and Dentistry at University of Louvain, who took part in our study.

Contributors $\mathrm{CO}$ 'T and HB conceived and designed the study. HB, NFAK and CO'T collected the data. DB, GR, HB, NFAK and CO'T analysed the data. HB and CO'T wrote the manuscript. DB, GR, HB, NFAK and $C O^{\prime} T$ critically revised the manuscript for important intellectual content. All authors commented and approved the manuscript.

Funding The authors have not declared a specific grant for this research from any funding agency in the public, commercial or not-for-profit sectors.

Competing interests None declared.

Patient consent for publication Not required.

Ethics approval This study received approval from the Clinical Research Ethics Committee of the Cork Teaching Hospitals (ecm6(ii)06/12/16).

Provenance and peer review Not commissioned; externally peer reviewed.

Data availability statement Data are available upon reasonable request. Deidentified participant data are available upon reasonable request from the corresponding author.

Supplemental material This content has been supplied by the author(s). It has not been vetted by BMJ Publishing Group Limited (BMJ) and may not have been peer-reviewed. Any opinions or recommendations discussed are solely those of the author(s) and are not endorsed by BMJ. BMJ disclaims all liability and responsibility arising from any reliance placed on the content. Where the content includes any translated material, BMJ does not warrant the accuracy and reliability of the translations (including but not limited to local regulations, clinical guidelines, terminology, drug names and drug dosages), and is not responsible for any error and/or omissions arising from translation and adaptation or otherwise.

Open access This is an open access article distributed in accordance with the Creative Commons Attribution Non Commercial (CC BY-NC 4.0) license, which permits others to distribute, remix, adapt, build upon this work non-commercially, and license their derivative works on different terms, provided the original work is properly cited, appropriate credit is given, any changes made indicated, and the use is non-commercial. See: http://creativecommons.org/licenses/by-nc/4.0/.

ORCID iDs

Deirdre Bennett http://orcid.org/0000-0002-4469-9138

Colm 0'Tuathaigh http://orcid.org/0000-0003-1365-1606

\section{REFERENCES}

1 Kim SS, Kaplowitz S, Johnston MV. The effects of physician empathy on patient satisfaction and compliance. Eval Health Prof 2004;27:237-51.

2 Hojat M, Louis DZ, Markham FW, et al. Physicians' empathy and clinical outcomes for diabetic patients. Acad Med 2011;86:359-64.

3 Lelorain S, Cattan S, Lordick F, et al. In which context is physician empathy associated with cancer patient quality of life? Patient Educ Couns 2018;101:1216-22.

4 Wang $\mathrm{H}$, Kline JA, Jackson BE, et al. Association between emergency physician self-reported empathy and patient satisfaction. PLoS One 2018;13:e0204113.

5 Zenasni F, Boujut E, Woerner A, et al. Burnout and empathy in primary care: three hypotheses. Br J Gen Pract 2012;62:346-7.

6 Yuguero O, Ramon Marsal J, Esquerda M, et al. Association between low empathy and high burnout among primary care physicians and nurses in Lleida, Spain. Eur J Gen Pract 2017;23:4-10. 
7 Wilkinson $\mathrm{H}$, Whittington R, Perry L, et al. Examining the relationship between burnout and empathy in healthcare professionals: a systematic review. Burn Res 2017;6:18-29.

8 Gleichgerrcht E, Decety J. Empathy in clinical practice: how individual dispositions, gender, and experience moderate empathic concern, burnout, and emotional distress in physicians. PLoS One 2013;8:e61526.

9 Hojat M, Mangione S, Nasca TJ, et al. Empathy scores in medical school and ratings of empathic behavior in residency training 3 years later. J Soc Psychol 2005;145:663-72.

10 Chen DCR, Pahilan ME, Orlander JD. Comparing a self-administered measure of empathy with observed behavior among medical students. J Gen Intern Med 2010;25:200-2.

11 Smith KE, Norman GJ, Decety J. The complexity of empathy during medical school training: evidence for positive changes. Med Educ 2017;51:1146-59.

12 Dohrenwend AM. Defining empathy to better teach, measure, and understand its impact. Acad Med 2018;93:1754-6.

13 Morse JM, Anderson G, Bottorff JL, et al. Exploring empathy: a conceptual fit for nursing practice? Image J Nurs Sch 1992;24:273-80.

14 Halpern J. What is clinical empathy? J Gen Intern Med 2003;18:670-4.

15 Quince T, Thiemann P, Benson J, et al. Undergraduate medical students' empathy: current perspectives. Adv Med Educ Pract 2016;7:443-55.

16 Hojat M, Mangione S, Nasca TJ, et al. The Jefferson scale of physician empathy: development and preliminary psychometric data. Educ Psychol Meas 2001;61:349-65.

17 Hojat M, LaNoue M. Exploration and confirmation of the latent variable structure of the Jefferson scale of empathy. Int J Med Educ 2014;5:73-81.

18 Di Lillo M, Cicchetti A, Lo Scalzo A, et al. The Jefferson scale of physician empathy: preliminary psychometrics and group comparisons in Italian physicians. Acad Med 2009;84:1198-202.

19 O'Connor K, King R, Malone KM, et al. Clinical examiners, simulated patients, and student self-assessed empathy in medical students during a psychiatry objective structured clinical examination. Acad Psychiatry 2014;38:451-7.

20 Berg K, Blatt B, Lopreiato J, et al. Standardized patient assessment of medical student empathy: ethnicity and gender effects in a multiinstitutional study. Acad Med 2015;90:105-11.

21 Bernardo MO, Cecílio-Fernandes D, Costa P, et al. Physicians' self-assessed empathy levels do not correlate with patients assessments. PLoS One 2018:13:e0198488.

22 Colliver JA, Conlee MJ, Verhulst SJ, et al. Reports of the decline of empathy during medical education are greatly exaggerated: a reexamination of the research. Acad Med 2010;85:588-93.

23 Davis MH. A multidimensional approach to individual differences in empathy. JSAS Catalog Select Doc Psychol 1980;10:85.

24 Costa P, de Carvalho-Filho MA, Schweller M, et al. Measuring medical students' empathy: exploring the underlying constructs of and associations between two widely used self-report instruments in five countries. Acad Med 2017;92:860-7.

25 Stansfield RB, Schwartz A, O'Brien CL, et al. Development of a metacognitive effort construct of empathy during clinical training: a longitudinal study of the factor structure of the Jefferson scale of empathy. Adv Health Sci Educ Theory Pract 2016;21:5-17.

26 Decety J, Jackson PL. The functional architecture of human empathy. Behav Cogn Neurosci Rev 2004;3:71-100.

27 Samson D, Apperly IA, Braithwaite JJ, et al. Seeing it their way: evidence for rapid and involuntary computation of what other people see. J Exp Psychol Hum Percept Perform 2010;36:1255-66.

28 Bukowski $\mathrm{H}$. The neural correlates of visual perspective taking: a critical review. Curr Behav Neurosci Rep 2018;5:189-97.

29 Mattan BD, Rotshtein P, Quinn KA. Empathy and visual perspectivetaking performance. Cogn Neurosci 2016;7:170-81.

30 Bukowski H, Samson D. New insights into the inter-individual variability in perspective taking. Vision 2017;1. doi:10.3390/ vision1010008. [Epub ahead of print: 03 Jan 2017].

31 Lawrence EJ, Shaw P, Baker D, et al. Measuring empathy: reliability and validity of the empathy quotient. Psychol Med 2004;34:911-20.

32 Kataoka HU, Koide N, Ochi K, et al. Measurement of empathy among Japanese medical students: psychometrics and score differences by gender and level of medical education. Acad Med 2009;84:1192-7.
33 Magalhães E, Salgueira AP, Costa $\mathrm{P}$, et al. Empathy in senior year and first year medical students: a cross-sectional study. BMC Med Educ 2011;11:52

34 Song G, Tung J, Ping YS. Complex and novel determinants of empathy change in medical students. Korean $\mathrm{J} \mathrm{Med} \mathrm{Educ}$ 2012;28:67-78.

35 Dehning S, Girma E, Gasperi S, et al. Comparative cross-sectional study of empathy among first year and final year medical students in Jimma University, Ethiopia: steady state of the heart and opening of the eyes. BMC Med Educ 2012;12:34.

36 Bukowski $\mathrm{H}$. What influences perspective taking? A dynamic and multidimensional approach [doctoral dissertation. Louvain-La-Neuve: University of Louvain, 2014

37 Bukowski H, Samson D. Can emotions influence level-1 visual perspective taking? Cogn Neurosci 2016;7:182-91.

38 Deliens G, Bukowski H, Slama H, et al. The impact of sleep deprivation on visual perspective taking. J Sleep Res 2018;27:175-83.

39 Bukowski H, Tik M, Silani G, et al. When differences matter: rTMS/ fMRI reveals how differences in dispositional empathy translate to distinct neural underpinnings of self-other distinction in empathy. Cortex 2020;128:143-61.

40 Pohl CA, Hojat M, Arnold L. Peer nominations as related to academic attainment, empathy, personality, and specialty interest. Acad Med 2011;86:747-51

41 Bukowski H, Hietanen JK, Samson D. From gaze cueing to perspective taking: revisiting the claim that we automatically compute where or what other people are looking at. Vis cogn 2015;23:1020-42.

42 Bukowski H, Samson D. Automatic imitation is reduced in narcissists but only in egocentric perspective-takers. Acta Psychol 2021:213:103235.

43 Lamm C, Bukowski H, Silani G. From shared to distinct self-other representations in empathy: evidence from neurotypical function and socio-cognitive disorders. Philos Trans R Soc Lond B Biol Sci 2016;371:20150083.

44 Batson CD, Fultz J, Schoenrade PA. Distress and empathy: two qualitatively distinct vicarious emotions with different motivational consequences. J Pers 1987;55:19-39.

45 Barry CT, Lui JHL, Anderson AC. Adolescent narcissism, aggression, and prosocial behavior: the relevance of socially desirable responding. J Pers Assess 2017:99:46-55.

46 Campbell WK, Sedikides C, Reeder GD, et al. Among friends? an examination of friendship and the self-serving bias. Br J Soc Psychol 2000;39 (Pt 2:229-39.

47 Ritter K, Dziobek I, Preissler S, et al. Lack of empathy in patients with narcissistic personality disorder. Psychiatry Res 2011;187:241-7.

$48 \mathrm{Harsch} \mathrm{HH}$. The role of empathy in medical students' choice of specialty. Acad Psychiatry 1989;13:96-8.

49 Murphy BA, Lilienfeld SO. Are self-report cognitive empathy ratings valid proxies for cognitive empathy ability? negligible meta-analytic relations with behavioral task performance. Psychol Assess 2019;31:1062-72.

50 Israelashvili J, Sauter D, Fischer A. How well can we assess our ability to understand others' feelings? beliefs about taking others perspectives and actual understanding of others' emotions. Front Psychol 2019;10:2475.

51 Haight SJ, Chibnall JT, Schindler DL, et al. Associations of medical student personality and health/wellness characteristics with their medical school performance across the curriculum. Acad Med 2012;87:476-85.

52 Bernardo MO, Cecilio-Fernandes D, Lima ARdeA, et al. Investigating the relation between self-assessment and patients' assessments of physicians-in-training empathy: a multicentric, observational, cross-sectional study in three teaching hospitals in Brazil. BMJ Open 2019;9:e029356

53 Wimmers PF, Stuber ML. Assessing medical students' empathy and attitudes towards patient-centered care with an existing clinical performance exam (OSCE). Procedia Soc Behav Sci 2010;2:1911-3.

54 Berg K, Majdan JF, Berg D, et al. Medical students' self-reported empathy and simulated patients' assessments of student empathy: an analysis by gender and ethnicity. Acad Med 2011;86:984-8.

55 LaNoue MD, Roter DL. Exploring patient-centeredness: the relationship between self-reported empathy and patientcentered communication in medical trainees. Patient Educ Couns 2018;101:1143-6. 